Brit. J. vener. Dis. (1958), 34, 101.

\title{
ACUTE GONOCOCCAL AND NON-GONOCOCCAL URETHRITIS*

\author{
SOME ASPECTS OF THEIR MEDICO-SOCIAL PATTERN
}

\author{
BY \\ W. V. MACFARLANE (Physician in charge) \\ AND \\ HILDA M. JOHNS (Almoner) \\ Department of Venereology, Newcastle General Hospital, Newcastle-upon-Tyne
}

In recent years the incidence of non-gonococcal urethritis (N.G.U.) has increased and in view of this it was decided that, when a diagnosis of N.G.U. was established, patients should be interrogated about their contacts as are those with gonorrhoea.

\section{Material}

The medical and social data of the first 100 men with N.G.U. registering after October 31, 1955 were compared with those of a like number suffering from gonorrhoea. As more patients attended with gonorrhoea the first one to register after every N.G.U. case was selected regardless of any other circumstances.

\section{Results}

Age.-The ratio of gonorrhoea to N.G.U. in men under the age of 30 years was $3: 2$, but this was reversed in men over the age of 40 . The youngest patient was a boy of 17 years with gonorrhoea and the oldest was a man of 60 years with N.G.U. (Table I). Only two of the fourteen patients aged 20 or under had had previous venereal infections; both were in the gonorrhoea group and one of them was a foreign merchant seaman aged 20 who had been infected eight times previously.

* Received for publication November 21, 1957
Civil Status. - It will be noted that the numbers of men who were single or married differed only slightly in the two groups (Table 1). The proportion of marriages which had ended in separation or divorce was considerably higher in the gonorrhoea group although the total numbers are small; 20 per cent. of the marriages of the men with gonorrhoea had broken down (eight out of forty men) as compared with 9 per cent. of those with N.G.U. (four out of 46).

The large group of single men (54) with N.G.U. and in particular the 35 men who were under 30 years of age requires further investigation, and this will be dealt with later. The chief difference in age and civil status occurred in the married men; seventeen out of 39 with N.G.U. were over 40 years as compared with three out of thirty with gonorrhoea. Only eighteen men of the 200 were not British, six with N.G.U. and twelve with gonorrhoea. They came from twelve different countries.

Occupation.-The majority of the patients had a stable home background; 74 with N.G.U. and 66 with gonorrhoea were employed in occupations which did not involve their being absent from their home (non-itinerant), but 26 with N.G.U. and 34 with gonorrhoea were frequently away (itinerant).

TABLE I

AGE AND CIVIL STATE OF 200 PATIENTS WITH URETHRITIS

\begin{tabular}{|c|c|c|c|c|c|c|c|c|c|c|c|c|c|}
\hline \multirow{2}{*}{$\begin{array}{l}\text { Diagnosis } \\
\text { Civil Status }\end{array}$} & \multirow{2}{*}{$\cdots$} & \multirow{2}{*}{$\begin{array}{l}\cdots \\
\cdots\end{array}$} & \multirow{2}{*}{$\cdots$} & \multicolumn{5}{|c|}{ Non-Gonococcal Urethritis } & \multicolumn{5}{|c|}{ Gonorrhoea } \\
\hline & & & & Single & Married & Widowed & $\begin{array}{c}\text { Separated } \\
\text { or } \\
\text { Divorced }\end{array}$ & Total & Single & Married & Widowed & $\begin{array}{c}\text { Separated } \\
\text { or } \\
\text { Divorced }\end{array}$ & Total \\
\hline \multirow[t]{2}{*}{$\begin{array}{l}\text { Age } \\
\text { (yrs) }\end{array}$} & $\begin{array}{l}20 \text { and under } \\
21-30 \ldots \\
31-40 \ldots \\
41 \text { and Over }\end{array}$ & $\begin{array}{l}\cdots \\
\cdots \\
\cdots\end{array}$ & $\begin{array}{l}\cdots \\
\cdots \\
\cdots\end{array}$ & $\begin{array}{r}5 \\
30 \\
16 \\
3\end{array}$ & $\begin{array}{r}-6 \\
16 \\
17\end{array}$ & $\begin{array}{r}-1 \\
1 \\
1\end{array}$ & $\begin{array}{l}-1 \\
2 \\
1\end{array}$ & $\begin{array}{r}5 \\
38 \\
35 \\
22\end{array}$ & $\begin{array}{r}9 \\
36 \\
13 \\
2\end{array}$ & $\begin{array}{r}\overline{13} \\
14 \\
3\end{array}$ & $\overline{-}$ & $\begin{array}{r}-3 \\
2 \\
3\end{array}$ & $\begin{array}{r}9 \\
52 \\
31 \\
8\end{array}$ \\
\hline & Total & . & . & 54 & 39 & 3 & 4 & 100 & 60 & 30 & 2 & 8 & 100 \\
\hline
\end{tabular}


The greater number of men in the itinerant section had gonorrhoea but in the non-itinerant group the majority suffered from N.G.U. The younger men out-numbered the older in the itinerant section and this was especially true of those with gonorrhoea. In the non-itinerant section the majority of those aged over 30 had N.G.U. and those under 30 had gonorrhoea (Table II).

There are four groups which seem to call for attention: seamen, black-coated workers, artisans, and labourers. The seamen and the artisans appear chiefly in the gonorrhoea group, whereas the blackcoated workers and the labourers are chiefly in the group with N.G.U. It is somewhat surprising that the commercial travellers and the transport workers in the N.G.U. group exceed those with gonorrhoea, but the numbers are small.

Of the married men with N.G.U. one quarter were itinerant, whereas of the married men with gonorrhoea one half were itinerant.

Consorts.-As it is not always easy to determine the incubation period in N.G.U., patients were questioned about their contacts over the preceding 3 months: 91 per cent. gave an incubation period of less than 4 weeks, 46 per cent. occurring within one week. Of those found to have acute gonococcal urethritis the incubation period in 92 per cent. was within 2 weeks, 74 per cent. occurring within the first week.

In contrast with the incidence in the gonorrhoea group, sexual promiscuity was less noticeable in the N.G.U. group; thus, 80 per cent. of the latter had only one contact compared with 58 per cent. in the former, while in the "other than married" categories the respective figures were 90 per cent. and 70 per cent. None of the N.G.U. patients had more than two contacts and amongst those who were single, widowed or separated, the incidence of promiscuity was only one-third of that in the gonorrhoea group (Table III).

Of seven married men with gonorrhoea who had extra-marital risks, one had two consorts, neither being his wife, the remaining six each having one. Barely half the men with N.G.U. had extra-marital contacts, whereas 27 out of 30 in the gonorrhoea group had extra-marital risks. Of the married men with extra-marital contacts, one-third of those with N.G.U. were itinerant, and one-half of those with gonorrhoea. There were three cases of sodomy amongst the $\mathbf{2 0 0}$ men; all three had gonorrhoea, and one had two male contacts (Table IV, opposite).

In 34 men with N.G.U. and 57 with acute gonorrhoea, promiscuity was associated with alcohol.

TABLE II

OCCUPATION AND AGE

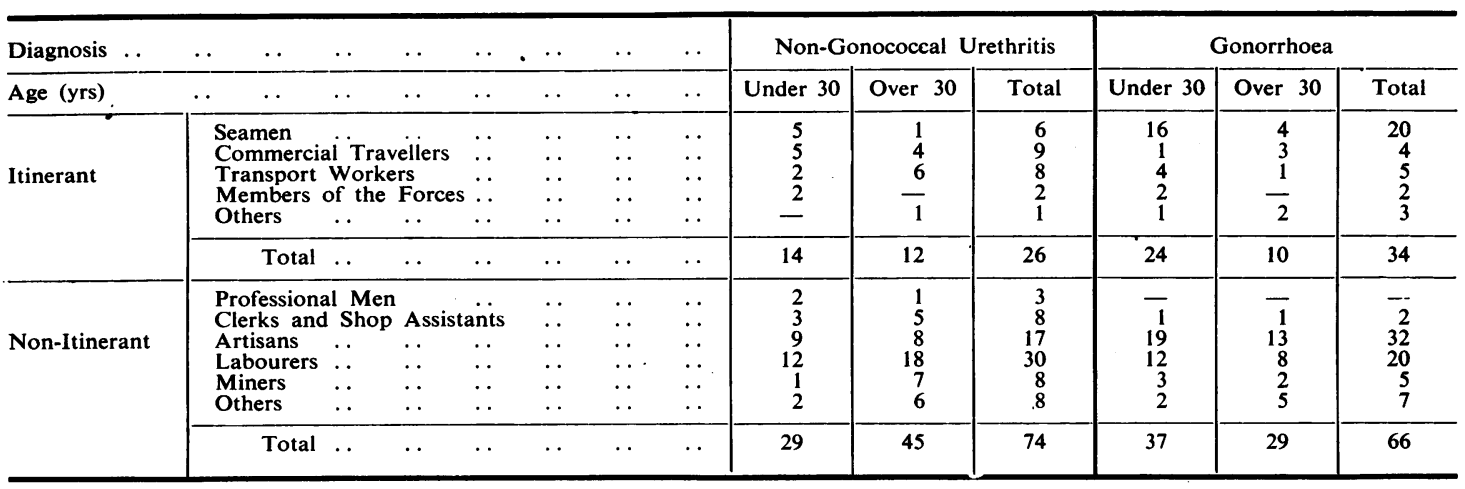

TABLE III

CIVIL STATUS AND NUMBER OF CONSORTS

\begin{tabular}{|c|c|c|c|c|c|c|c|c|c|c|c|c|c|}
\hline \multirow{2}{*}{\multicolumn{2}{|c|}{$\frac{\text { Diagnosis }}{\text { No. of Consorts }}$}} & \multirow{2}{*}{$\cdots$} & \multirow{2}{*}{$\cdots$} & \multirow{2}{*}{$\cdots$} & \multirow{2}{*}{$\cdots$} & \multicolumn{4}{|c|}{ Non-Gonococcal Urethritis } & \multicolumn{4}{|c|}{ Gonorrhoea } \\
\hline & & & & & & One & Two & Over Two & Total & One & Two & Over Two & Total \\
\hline \multirow[t]{2}{*}{ Civil Status } & $\begin{array}{l}\text { Mar } \\
\text { Sing } \\
\text { Sep }\end{array}$ & $\begin{array}{l}\text { ied } \\
\text { ated }\end{array}$ & $\begin{array}{l}\text { Wido } \\
\text { and } \mathrm{D}\end{array}$ & $\begin{array}{l}\text { ers } \\
\text { orced }\end{array}$ & $\begin{array}{l}\cdots \\
\cdots \\
\cdots\end{array}$ & $\begin{array}{r}27 \\
50 \\
3\end{array}$ & $\begin{array}{r}12 \\
5 \\
1\end{array}$ & $\overline{-}$ & $\begin{array}{r}39 \\
55 \\
4\end{array}$ & $\begin{array}{r}9 \\
42 \\
7\end{array}$ & $\begin{array}{r}20 \\
5 \\
-\end{array}$ & $\begin{array}{r}1 \\
15 \\
1\end{array}$ & $\begin{array}{r}30 \\
62 \\
8\end{array}$ \\
\hline & & Total & . & .. & . & 80 & 18 & - & $98 *$ & 58 & 25 & 17 & 100 \\
\hline
\end{tabular}

*In two instances exposure was denied within the preceding 3 months. 
TABLE IV

CIVIL STATUS AND RFLATIONSHIP TO CONSORT(S)

\begin{tabular}{|c|c|c|c|}
\hline Diagnosis & $\cdots \quad \cdots$ & $\begin{array}{l}\text { Non- } \\
\text { Gonococcal } \\
\text { Urethritis }\end{array}$ & Gonorrhoea \\
\hline \multirow[t]{2}{*}{ Married } & $\begin{array}{l}\text { Marital only } \ldots \\
\text { Extra-marital only } \\
\text { Extra-marital and marital }\end{array}$ & $\begin{array}{r}21 \\
6 \\
12\end{array}$ & $\begin{array}{r}3 \\
7 \\
20\end{array}$ \\
\hline & Total $\ldots \quad \ldots$ & 39 & 30 \\
\hline \multirow[t]{2}{*}{ All Others } & $\begin{array}{lrr}\text { Regular consort only } & \ldots \\
\text { One casual consort } & \ldots \\
\text { Regular and casual con- } \\
\text { sorts . }\end{array} \begin{array}{l}\text { More than one } \\
\text { Morual } \\
\text { consort } \\
\begin{array}{l}\text { Sodomy } \\
\text { No consort in last }\end{array}\end{array}$ & $\begin{array}{r}20 \\
33 \\
5 \\
\frac{1}{2}\end{array}$ & $\begin{array}{r}9 \\
38 \\
6 \\
14 \\
3 \\
-\end{array}$ \\
\hline & Total .. & 61 & 70 \\
\hline
\end{tabular}

The figure for gonorrhoea is lower than that $(77$ per cent. noted in the previous survey amongst patients attending this department (Macfarlane, 1948).

Reason for Attendance.- - Those who had regular liaisons, married men and 50 per cent. of the single men with regular consorts usually were referred to this department by their General Practitioners. Where men had casual consorts the bulk of the patients attended here of their own accord as they more readily suspected they had acquired venereal infection (TableV).

\section{Previous Venereal Infections}

In the N.G.U. group, 24 men had a previous history of venereal disease, 23 having had gonorrhoea and one syphilis. For the gonorrhoea group the number was 38 ; all 38 had had gonorrhoea and two of these had also had syphilis. A previous history of N.G.U. was reported by eighteen patients with N.G.U. and one with gonorrhoea.

Concomitantly acquired gonorrhoea was noted by Gartman and Leibovitz (1955) in 79 of 435 patients with N.G.U., but there was no evidence of it in our series, the interval between the previous gonococcal infection and present N.G.U. varying between 10 and 140 months.

Latent syphilis was discovered in one patient who gave a history of having had an untreated primary lesion in 1930.

The eighteen patients with a previous history of N.G.U. were interrogated about their original infections. The possibility of re-infection cannot be entirely ruled out, since in four patients, each of whom had his regular consort, the interval between infections was 2 or more months. Eight had different consorts, one denied having a consort at all, and in the remaining five, data were not forthcoming. None of the 200 patients had therefore acquired a dual venereal infection.

\section{Previous Antibiotic Therapy}

Over half the men had had antibiotic therapy before attendance, 50 in the N.G.U. group, and 56 in the gonorrhoea group. In the former, 22 had received various antibiotics for venereal infection, 8 for N.G.U. and twenty for other reasons. The corresponding figures for gonorrhoea being 37,1 , and 18 respectively. Two men in the gonorrhoea group with a past history of syphilis had been treated in the pre-penicillin era. These statistics resemble those for all patients attending this department, in that approximately half have had previous antibiotic therapy for one reason or another.

\section{Clinical Observations and Treatment}

In view of the conclusions determined at a meeting of the International Union against the Venereal Diseases and Treponematoses (September, 1954), the aetiology of N.G.U. was not investigated other than by routine smears and cultures. Dark-ground investigation of pus was done but the results were discouraging.

At their initial attendance, 62 per cent. of men with gonococcal urethritis were symptomatic, as compared with 37 per cent. in the N.G.U. series. Dysuria was the commonest symptom, being found

TABLE V

REASONS FOR ATTENDANCE AND RELATIONSHIP TO CONSORT(S)

\begin{tabular}{|c|c|c|c|c|c|c|c|c|c|c|c|c|}
\hline \multirow{2}{*}{$\begin{array}{l}\text { Diagnosis } \\
\text { Reason for }\end{array}$} & \multirow{2}{*}{ A } & \multirow{2}{*}{$\cdots$} & \multirow{2}{*}{$\cdots$} & \multirow{2}{*}{$\cdots$} & \multirow{2}{*}{$\begin{array}{l}\cdots \\
\cdots\end{array}$} & \multirow{2}{*}{$\begin{array}{l}\cdots \\
\cdots\end{array}$} & \multicolumn{3}{|c|}{ Non-Gonococcal Urethritis } & \multicolumn{3}{|c|}{ Gonorrhoea } \\
\hline & & & & & & & $\begin{array}{l}\text { Own } \\
\text { accord }\end{array}$ & $\begin{array}{c}\text { General } \\
\text { Practitioner }\end{array}$ & Total & $\begin{array}{l}\text { Own } \\
\text { accord }\end{array}$ & $\begin{array}{c}\text { General } \\
\text { Practitioner }\end{array}$ & Total \\
\hline Married & $\begin{array}{l}\text { With m } \\
\text { With ex }\end{array}$ & $\begin{array}{l}\text { marital co } \\
\text { extra-mari }\end{array}$ & $\begin{array}{l}\text { act o } \\
\text { con }\end{array}$ & & & $\begin{array}{l}\cdots \\
\cdots\end{array}$ & $\begin{array}{r}9 \\
15\end{array}$ & $\begin{array}{r}12 \\
3\end{array}$ & $\begin{array}{l}21 \\
18\end{array}$ & 21 & $\begin{array}{l}1 \\
6\end{array}$ & $\begin{array}{r}3 \\
27\end{array}$ \\
\hline All Others & $\begin{array}{l}\text { With re } \\
\text { With }\end{array}$ & $\begin{array}{l}\text { regular co } \\
\text { casual con }\end{array}$ & $\begin{array}{l}\text { ort o } \\
\text { rt or }\end{array}$ & $\begin{array}{l}\text { y } \\
\text { nore }\end{array}$ & $\ddot{a n}$ & $\ldots$ & $\begin{array}{l}10 \\
29\end{array}$ & $\begin{array}{l}10 \\
12\end{array}$ & $\begin{array}{l}20 \\
41\end{array}$ & $\begin{array}{r}4 \\
51\end{array}$ & $\begin{array}{r}5 \\
10\end{array}$ & $\begin{array}{r}9 \\
61\end{array}$ \\
\hline Total & $\ldots$ & . & $\ldots$ & $\ldots$ & . & . & 63 & 37 & 100 & 78 & 22 & 100 \\
\hline
\end{tabular}


in 60 per cent. and 32 per cent. respectively. Posterior urethritis occurred in 24 per cent. of those reporting with gonorrhoea compared with 10 per cent. in the N.G.U. group. Two had acute gonococcal prostatitis, but no evidence of epididymitis or arthritis was found, whereas in the N.G.U. series two had epididymitis and one had arthritis. The last patient responded to artificially induced pyrexia after antibiotic therapy had failed.

Eighty men were treated with terramycin $(250 \mathrm{mg}$. 6-hrly. for 3 days); a further fifteen, in addition to terramycin treatment, received anterior urethral irrigations of mercury oxycyanide $(1: 10,000)$. Four failures were recorded, but all responded to streptomycin (1g. daily for 3 days) together with Sulphatriad (5g. daily for 5 days). Failure implied a persistent urethral discharge showing an average polymorph content of at least six per field together with hazy urine, especially the "first urine". Alternatively, the urine may have shown numerous specks. One patient showed intolerance to terramycin which responded to appropriate measures.

The remaining five patients with uncomplicated N.G.U. responded satisfactorily to mercury oxycyanide irrigations alone.

Many authorities believe that N.G.U. may resolve spontaneously, but we believe such patients attending a venereal diseases department need not only reassurance but also treatment.

The consorts of men with N.G.U. were only followed up if the patient himself was able and willing to bring his consort. As it has not been proved conclusively that N.G.U. is transmissible, it was felt inadvisable to ask the contact-tracers to seek out the casual or unknown promiscuous women whose co-operation is needed when they are named as the source of a venereal disease infection. This resulted, therefore, in the women who were examined being either the wives or the regular consorts of the men (Table VI).

Twenty N.G.U. contacts reported for examination, of whom twelve had vaginal discharge, but in only three instances could a cause be found, namely
TABLE VI

CONTACTS OR CONSORTS

\begin{tabular}{|c|c|c|c|c|c|c|}
\hline Diagnosis & $\ldots$ & . & . & $\cdots$ & $\begin{array}{l}\text { Non- } \\
\text { Gonococcal } \\
\text { Urethritis }\end{array}$ & Gonorrhoea \\
\hline \multicolumn{2}{|c|}{ Total Contacts Named } & $\ldots$ & $\ldots$ & $\ldots$ & 116 & 142 \\
\hline $\begin{array}{l}\text { Not } \\
\text { Sought }\end{array}$ & \multicolumn{2}{|c|}{$\begin{array}{l}\text { Out of area } \\
\text { Too vague } \\
\text { Inadvisable }\end{array}$} & $\begin{array}{l}\cdots \\
\cdots\end{array}$ & $\begin{array}{l}\cdots \\
\cdots \\
\cdots\end{array}$ & $\begin{array}{l}27 \\
30 \\
27\end{array}$ & $\begin{array}{l}24 \\
33 \\
-\end{array}$ \\
\hline \multicolumn{3}{|c|}{ Before Incubation Period } & $\cdots$ & $\cdots$ & - & 18 \\
\hline \multicolumn{3}{|c|}{ Total Contacts Sought } & $\cdots$ & . & 32 & 67 \\
\hline $\begin{array}{l}\text { Contacts } \\
\text { Sought }\end{array}$ & \multicolumn{3}{|c|}{$\begin{array}{l}\text { Found . } \\
\text { Refused to attend } \\
\text { Examined }\end{array}$} & $\begin{array}{l}\cdots \\
\cdots \\
\cdots\end{array}$ & $\begin{array}{r}26 \\
6 \\
20\end{array}$ & $\begin{array}{r}52 \\
5 \\
47\end{array}$ \\
\hline $\begin{array}{l}\text { Results of } \\
\text { Examination }\end{array}$ & \multicolumn{4}{|c|}{$\begin{array}{l}\text { Gonorrhoea } \\
\text { Gonorrhoea and syphilis } \\
\text { Trichomonas vaginalis } \\
\text { No venereal disease }\end{array}$} & $\frac{-}{3}$ & $\begin{array}{r}38 \\
2 \\
7\end{array}$ \\
\hline
\end{tabular}

Trichomonas vaginalis infestation. Of 47 women named by 43 men with gonorrhoea who were examined, forty were found to have gonococcal infection and seven were negative on investigation. Two of those with gonorrhoea were found to have previously untreated latent syphilis.

When interrogating men who could not give the full name and address of their consorts, careful descriptions were obtained, and it was noted that not one of the 116 consorts of the men with N.G.U. was named by more than one man. Six gonorrhoea contacts were each named by two men in this survey and several others were well known as promiscuous women.

These numbers are too small to permit any firm conclusions to be drawn, but it is noticeable that a larger proportion of the women in the gonorrhoea group were separated or divorced than in the N.G.U. group. In the N.G.U. group, five women were separated and one divorced, while in the gonorrhoea group, thirteen were separated and three divorced. In neither group were there any widows (Table VII).

In the N.G.U. group, half of the women were engaged in home duties. Four were employed in shops or as clerks, five in factories, and two in other

TABLE VII

AGE AND CIVIL STATUS OF CONSORTS IDENTIFIED

\begin{tabular}{|c|c|c|c|c|c|c|c|c|c|c|c|c|}
\hline \multirow{2}{*}{$\frac{\text { Diagnosis }}{\text { Civil Status }}$} & \multirow{2}{*}{ 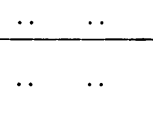 } & \multirow{2}{*}{$\cdots$} & \multirow{2}{*}{$\cdots$} & \multirow{2}{*}{$\cdots$} & \multicolumn{4}{|c|}{ Non-Gonococcal Urethritis } & \multicolumn{4}{|c|}{ Gonorrhoea } \\
\hline & & & & & Single & Married & $\begin{array}{l}\text { Separated } \\
\text { and } \\
\text { Divorced }\end{array}$ & Total & Single & Married & $\begin{array}{l}\text { Separated } \\
\text { and } \\
\text { Divorced }\end{array}$ & Total \\
\hline \multirow[t]{2}{*}{ Age (yrs) } & \multicolumn{2}{|c|}{$\begin{array}{l}20 \text { and Under } \\
21-30 \ldots \\
31-40 \ldots \\
41 \text { and Over } .\end{array}$} & $\begin{array}{l}\ddot{ } \\
\ddot{*} \\
\dot{*}\end{array}$ & $\begin{array}{l}\cdots \\
\ddot{*} \\
\cdots\end{array}$ & $\begin{array}{r}2 \\
4 \\
1 \\
-\end{array}$ & $\begin{array}{l}-5 \\
6 \\
2\end{array}$ & $\begin{array}{l}-5 \\
1 \\
\end{array}$ & $\begin{array}{r}2 \\
14 \\
8 \\
2\end{array}$ & $\begin{array}{r}6 \\
4 \\
1 \\
\end{array}$ & $\begin{array}{r}1 \\
13 \\
8 \\
2\end{array}$ & $\begin{array}{r}\overline{10} \\
4 \\
2\end{array}$ & $\begin{array}{r}7 \\
27 \\
13 \\
4\end{array}$ \\
\hline & Total & . & $\ldots$ & $\ldots$ & 7 & 13 & 6 & 26 & 11 & 24 & 16 & 51 \\
\hline
\end{tabular}


occupations. There was only one prostitute. In the gonorrhoea group, two-fifths of the women were engaged in home duties, but in this group there were twenty prostitutes, a significant difference from the N.G.U. group. The other twelve women were employed in various capacities.

In the N.G.U. group, none of the women identified had a history of any venereal infection, but in the gonorrhoea group thirteen out of 51 women had previously had gonorrhoea and one of them had also had syphilis. It is not possible to give figures for the contacts who were not identified, as the patients' statements could not be verified, but it is noticeable that the tendencies revealed in the identified contacts are shown also in the unidentified, for instance the age group 21-30 predominated and there were more married women than any others. Again, there were far more prostitutes among the consorts of men with gonorrhoea than in the consorts of men with N.G.U.

Of the twenty women who were consorts of the men with N.G.U., eight had not had any pregnancies, twelve had had pregnancies of whom six stated their deliveries were natural, three women had among them eleven miscarriages to their husbands who were the N.G.U. patients, and three stated that there had been difficulties at the time of delivery.

\section{Discussion}

Excluding the higher incidence of symptoms in gonorrhoea (62 per cent.) than in N.G.U. (37 per cent.), and the higher incidence of posterior urethritis in gonorrhoea ( 24 per cent.) than in N.G.U. (10 per cent.), no striking clinical differences were noted.

However, other facts clearly emerged from this analysis; for example, N.G.U. was commonest in the later age groups and amongst labourers and black-coated workers, whereas gonorrhoea was more prevalent amongst merchant seamen and artisans. Married men who remained faithful to their wives were more frequently in the N.G.U. class. Promiscuity was found in both groups, but to a much greater extent among the men with gonorrhoea; it was more frequently noted in the artisan class, the itinerants, and those who indulged in alcohol regularly.

Less than one-fifth of men with gonorrhoea had a stable relationship, marital or otherwise, with their consorts, and by contrast less than one-fifth of those with N.G.U. had more than one consort. Whether married or single, the majority of men who came of their own accord had been exposed to risk.

Eleven married men who came of their own accord and denied an extra-marital risk are of interest. In the gonorrhoea group, one was a commercial traveller from another area who did not know a doctor here, and another denied a risk and, although his wife was not infected, continued to deny it despite this evidence. Of the N.G.U. group, four men had been treated previously in the clinic (one for gonorrhoea and three for N.G.U.), two others had had N.G.U. and had had hospital treatment elsewhere, two were nervous and feared it might be venereal disease, and the last man was friendly with a member of staff.

To us the most surprising feature is the relatively high incidence of single men with N.G.U. Our figure is 54 per cent.; an even higher proportion ( 59 per cent.) was found when analysing the records of 150 men who attended subsequent to the compilation of this paper. Comparing them with the married men with N.G.U., they were younger, a slightly higher proportion were itinerant, there were more heavy drinkers amongst them, and also more men with a previous history of venereal disease. Of these 54 single men, 48 had only one contact in the previous 3 months, and nineteen of these were either regular girl friends or liaisons; two more denied any contact in that period and only four had had more than one consort. On the other hand, twelve out of 39 married men had had two consorts. In this perhaps may lie the clue to the problem, as their sexual habits were more typical of married men than of the young single promiscuous men who form the majority of the patients of a venereal diseases clinic.

Because no consort was named a second time by any of the 100 men with N.G.U., a further 150 men with N.G.U. were interrogated, and still no woman has been named a second time. Among the contacts of the 100 men with gonorrhoea, however, six women were named twice.

\section{Conclusions}

It would appear that N.G.U. may be expected in older men, especially those who are married or in those who are single but have a regular consort; younger promiscuous men are more likely to acquire gonorrhoea.

\section{Summary}

Some aspects of the medico-social pattern in 100 men with acute gonococcal urethritis are compared with those in a similar number of men found to have N.G.U.

No striking medical differences were noted apart from the higher incidence of symptoms and posterior urethritis in men with gonorrhoea. 
Gonorrhoea was found to occur more frequently among younger men, the promiscuous, the itinerants, and those addicted to alcohol.

Conversely, N.G.U. was associated especially with married men who had had no extra-marital risk, and with those in the older age groups.

The high incidence of N.G.U. amongst single men, which was approximately the same as among those who had gonococcal urethritis, is worthy of note and a possible explanation is suggested.
No woman was named by more than one man with N.G.U. out of more than 250 interrogated. This absence of promiscuity among the N.G.U. contacts appears to be the only fundamental difference between the two groups. Other differences exist, but they are a matter of degree only.

\section{REFERENCES}

Gartman, E., and Leibovitz, A. (1955). Brit J. vener. Dis., 31, 92 Macfarlane, W. V. (1948). Publ. Hlth, 61, 157

International Union against the Venereal Diseases and Treponematoses (1954). Lancet, 2, 966 